\title{
Manifesto do Coletivo do NESEF em repúdio ao Projeto \\ "Escola sem Partido"
}

Curitiba, 20 de julho de 2016.

O Núcleo de Estudos e Pesquisas sobre o Ensino da Filosofia (Nesef/UFPR) dirige-se à Sociedade Brasileira e, de modo particular, às instituições de ensino a fim de demarcar seu posicionamento em relação ao projeto "Escola sem Partido" (2015) que é apoiado e sustentado pelo governo interino e golpista de Michel Temer.

O momento de instabilidade política que o país atravessa é agudizado pela crise do capitalismo mundial. Nesse cenário, uma série de medidas têm sido implementadas na contramão do interesse público das maiorias e dos direitos sociais amplos. Além dos vários ataques às conquistas históricas da classe trabalhadora, o governo golpista, sustentado por um séquito de parlamentares e empresários ultraconservadores tenciona intervir na espinha dorsal da organização do - ainda incipiente - Sistema Nacional de Educação, solapando os avanços que este incorporou nos últimos anos, sobretudo a partir da promulgação da Constituição de 1988.

Com efeito, o princípio da educação universal, laica, gratuita, pública, com qualidade epistemológica e, muito por isso, afirmada como direito social subjetivo, consubstancia os processos educativos que se pretendem, de fato, formadores. Nesse sentido, o caráter liberal-democrático da educação pública ofertada às maiorias é meio para que toda a sociedade, mais especialmente, a classe trabalhadora, seja sujeito do direito social à educação.

Os vários Projetos de Lei (PL) em tramitação atualmente, tomados em seu conjunto, subvertem a própria função social das escolas, faculdades e universidades públicas, posto que lhes extirpam seu caráter essencial, qual seja, o de serem instituições de socialização do conhecimento sistematizado. Ora, num Estado Democrático de Direito, a educação das maiorias, uma vez esvaziada dessa função e entregue a toda sorte de interesses mercantis e partidários, torna-se tão somente um simulacro.

A educação nos últimos tempos tem sofrido perdas severas. Os cortes de investimentos e gastos correntes atingiram em cheio o conjunto das políticas e programas educacionais para todos os níveis e modalidades de ensino. O PDE (Programa de Desenvolvimento Educacional), em vigor desde 2007, teve inúmeras alterações por conta dessas reversões. Ao mesmo tempo em que se limitam os investimentos diretos, torna-se flagrante a diminuição do controle social sobre as decisões do setor. As organizações civis que congregam os sujeitos e as instituições que historicamente detém o conhecimento teórico-prático sobre os problemas e as necessidades educacionais da sociedade brasileira - tais como Fóruns, Associações Docentes, Sindicatos de Professores e demais Trabalhadores em Educação -, não têm conseguido dialogar com o Governo Interino e sua base parlamentar. Essa lógica que une medidas unilaterais do governo e dos legisladores à ausência do debate democrático completa-se com a avassaladora abertura da educação pública ao mercado privado, deixando claro, nesse sentido, os reais interesses das atuais reconfigurações. 
Dos vários projetos em tramitação que tomam de assalto o sentido republicano e democrático da educação nacional, destaca-se o PL denominado eufemisticamente de "Escola sem partido". Idealizado pelo jurista ultraconservador e francamente adepto do Estado Mínimo para os trabalhadores, Miguel Nagib, o PL 867/2015 vem sendo popularizado entre os educadores como uma "Lei da Mordaça", porém suas intencionalidades escusas vão muito além do campo das ideias.

Apresentado no Congresso Nacional pelo Deputado Izalci Ferreira (PSDB-DF), cujo portfólio de PLs que destroem o caráter público e democrático da educação nacional é grande, o "Escola Sem Partido" granjeia uma maioria de apoiadores entre os parlamentares, haja vista o caráter essencialmente retrógrado e populista da composição do atual Parlamento Nacional. A força do PL vem principalmente, mas não só, de parlamentares evangélicos e católicos conservadores, os quais, em sua maioria, pertencem aos quadros do DEM, do PSC, do PSDB e do PMDB. Estes aliados aos lobistas que representam, no Congresso Nacional, os interesses dos grandes empresários e conglomerado, em nome de uma pretensa desideologização da educação brasileira, formam a linha de frente do PL 867/2015, que se caracteriza pela proposição da limitação do caráter da escola como instituição de formação humana integral e de socialização do conhecimento.

O "Escola Sem Partido" subverte a legislação vigente ao tomar como princípio uma suposta "neutralidade política, ideológica e religiosa do Estado" e uma incompreensível e subjetiva "liberdade de aprender, como projeção específica, no campo da educação, da liberdade de consciência". Como se não bastasse, a alusão à liberdade de consciência, assim entendida, como um pensamento isento de conteúdo e, portanto, de condições de elaboração de qualquer crítica, o PL assevera como "direito dos pais a que seus filhos recebam a educação moral que esteja de acordo com suas próprias convicções”, ou seja, a letra do PL, impõe uma educação diferente para cada indivíduo e, como tal ação é sabidamente não factível, na prática, o que salta à interpretação mais açudada desse princípio é sua intencionalidade, fortemente marcada pela fluidificação do conhecimento, pela banalização e esvaziamento dos conteúdos curriculares. De fato, o objetivo declarado do PL é extremamente ideológico ao tentar escamotear os interesses que o sustentam sob uma capa mal costurada de neutralidade. Ao apresentar-se como uma lei que proíbe as instituições educativas de veicularem qualquer "doutrinação" de cunho ideológico ou quaisquer conteúdos que possam entrar em conflito com as convicções religiosas e morais dos estudantes, o PL diz a que veio, ou seja, inibe flagrantemente, sob o eufemismo da liberdade imprecisa, a liberdade de ensinar e aprender, de fato, conteúdos relevantes tomados sob vieses plurais.

Ferindo de morte os princípios constitucionais que tratam dos direitos democráticos de expressão, de cátedra e de pensamento, o "Escola Sem Partido" propõe, a bem da verdade, um pensamento único, qual seja, o de seus idealizadores. É, portanto, uma tentativa de ideologização sem precedentes na história da educação nacional, superando, em seus conceitos, as leis mais conservadoras que vigoraram nos tempos da Ditadura Civil-Militar.

A educação, assim como todas as dimensões e organizações humanas e sociais, é ato político, porque ocorre entre pessoas em dado momento histórico, em dado contexto, com objetivos e condições determinadas. Logo, não há educação que não seja transpassada pelas ideologias, porque não há educação fora da história, fora do mundo, 
fora do movimento contraditório da sociedade onde ela ocorre. Dessa forma, entende-se que o "Escola Sem Partido" propõe que a escola negue a história, a cultura, enfim, o conhecimento e contente-se em ser tão somente um local de troca entre os saberes vagos do senso-comum, isentos de crítica e com interesse único de preparar mão de obra barata para uma possível empregabilidade, concretizando, assim, o Estado Autoritário Sem Escola.

Além do cinismo mencionado, a demonização da política, do fenômeno social do poder e do/a docente é outra marca do "Escola Sem Partido". Não por acaso, o PL, ao mesmo tempo em que abre as brechas para um ensino que prepara tão somente para um possível mercado de trabalho, concebe a política como algo negativo. É como se afirmasse que a inserção no mundo do poder, no mundo das decisões não deveria ser franqueada aos/às trabalhadores/as e seus filhos e filhas. É acintoso, por exemplo, a proibição de que o/a professor/a incite "os alunos a participar de manifestações, atos públicos e passeatas".

A desconfiança em relação ao/à docente e o sentido fascista inquisitorial do PL são perfeitamente expressos nos seguintes trechos: "as escolas afixarão nas salas de aula, nas salas dos professores e em locais onde possam ser lidos por estudantes e professores, cartazes com o conteúdo previsto no Anexo desta Lei, com, no mínimo, 70 centímetros de altura por 50 centímetros de largura, e fonte com tamanho compatível com as dimensões adotadas" e "As secretarias de educação contarão com um canal de comunicação destinado ao recebimento de reclamações relacionadas ao descumprimento desta Lei, assegurado o anonimato".

Elaborado por pessoas que não entendem nada de educação, que não têm com ela nenhum compromisso social, político ou ético; pessoas que, ao contrário desses qualificativos, veem a educação tão somente como um meio para ecoar suas próprias ideologias retrógradas e ampliar nichos de mercado, o "Escola Sem Partido", tem propagandeado suas teses de modo a ridicularizar os movimentos sociais e os grandes mentores intelectuais do ideal da educação pública, gratuita, laica, universal e com qualidade social.

Sob o eufemismo da "neutralidade", o Projeto, no seio do senso social comum têm granjeado apoios, o que sobremaneira preocupa ao conjunto dos educadores bem formados e informados, dos intelectuais da educação e dos movimentos sociais progressistas. Com efeito, as intencionalidades do "Escola Sem Partido", um verdadeiro ícone do totalitarismo, não são dadas a perceber claramente pela grande maioria da sociedade, posto que seus slogans se concentram numa indelével e imprecisa liberdade de consciência de aprender o que se deseja de acordo com convicções particulares. Com semelhante jogo de palavras, os lobistas que o alardeiam em blogs e redes sociais têm conseguido seduzir parte da sociedade. Outra estratégia dos conservadores tem sido aprovar as ideias-chave do "Escola Sem Partido" no varejo, isto é, nos Sistemas Municipais e Estaduais de Educação. Dessa forma, em centenas de municípios e, pelo menos, oito Estados da Federação, já tramitam ou já se aprovaram leis congêneres às proposições do Projeto.

Por fim, ressalta-se que o "Escola Sem Partido", além de romper com a função social da educação pública, esvaziar os seus conteúdos curriculares, tripudiar sobre o caráter profissional das diversas docências especializadas, propor sub-repticiamente um 
pensamento único e valorizar de forma velada o sentido mercantil da educação de massas, retira das instituições escolares sua identidade e sua autonomia.

Assim sendo, reafirmamos que: (1) a escola possui uma função social estabelecida democraticamente mediante conquistas sociais históricas e, como ente social e, por extensão, político, deve ser entendida, valorizada e estendida à totalidade dos/as cidadãos/ãs; (2) os professores/as são profissionais especializados da educação e não meros incitadores de ideologias; (3) a pluralidade de expressão e de ensino é necessária e, muito por isso, é, também, política, porque histórica e social; (4) não há escola sem conhecimento sistematizado, social e academicamente relevante, e todo conhecimento guarda um nexo político.

Considerando as razões acima expostas, rejeitamos em termos absolutos o projeto "Escola Sem Partido" e as intencionalidades que o sustentam, por entendemos que uma possível concretização de seus postulados afronta os mais elementares princípios do Estado Democrático de Direito e descaracteriza a educação escolar de seus sentidos mais fundamentais.

Saudações filosóficas. Membros do Coletivo do Nesef 